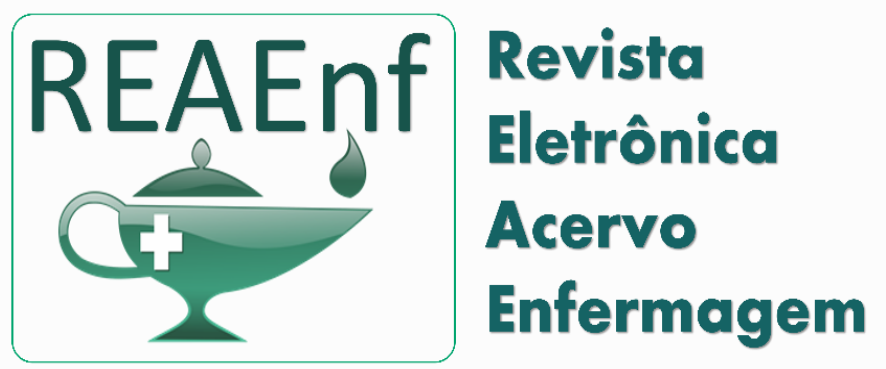

\section{ARTIGO ORIGINAL}

Recebido em: 7/2020

Aceito em: $8 / 2020$

Publicado em: 9/2020

\title{
Perfil de gestantes atendidas em um hospital público no interior paulista
}

\author{
Profile of pregnant women attended at a public hospital in the interior of São Paulo
}

Perfil de mujeres embarazadas atendidas en un hospital público en el interior paulista

Shirlene Pavelqueires ${ }^{1}$, Isabella Teixeira Rocha dos Santos ${ }^{1 *}$.

\begin{abstract}
Resumo: Objetivo deste estudo é identificar o perfil epidemiológico das gestantes atendidas em situação de urgências e emergências no hospital de referência de uma instituição pública do interior paulista. Baseada em pesquisa epidemiológica, retrospectiva, transversal de abordagem quantitativa do tipo exploratória e explicativa. Após análises, verificaram-se variáveis no perfil epidemiológico e amplos fatores de risco desse público que evolveram características socioeconômicas, morbidades pré-existentes e adquiridas até procedimentos envolvidos. Conclui-se que a procedência prevalece o munícipio estudado (72,2\%). Em sua maioria $(27,4 \%)$ tinham entre 20 e 24 anos. As principais causas de atendimento são as complicações em trabalho de parto e parto (22\%), que terminam em aborto (20\%), motivos ligados ao feto, cavidade amniótica e ao parto (14\%) e edema, proteinúria e transtornos hipertensivos na gravidez, no parto e no puerpério com $(1,8 \%)$. A via de parto cesárea foi responsável por $67,7 \%$ dos partos realizados e $62,8 \%$ dos procedimentos sendo a curetagem pósabortamento. Destaca-se os tratamentos para intercorrências na gravidez (92,8\%), para complicações relacionadas ao puerpério (3\%), cirúrgico de gravidez ectópica $(2,4 \%)$ e para edema, proteinúria e transtornos hipertensivos na gravidez, parto e puerpério (1\%). Constata-se um perfil característico da região não apresentando distinção das demais regiões do Brasil.
\end{abstract}

Palavras-chave: Gestantes, Emergências, Unidade hospitalar de ginecologia e obstetrícia.

Abstract: Objective of this study is identifying the epidemiological profile of pregnant women at risk in urgency and emergency in the reference hospital of a public institution in the interior of São Paulo. Based on an epidemiological, retrospective and quantitative approach of the exploratory and explanatory type were adopted. After analyses there were found variables in the epidemiological profile: socioeconomic factors, pre-existing morbidities and acquires up to procedures involved. Conclusion the origin prevails the studied municipality $(72,2 \%)$. Most of them $(27,4 \%)$ were between 20 and 24 years old. The main causes of care are complications in labor and childbirth (22\%), which end in abortion (20\%), reasons linked to the fetus, amniotic cavity and hypertensive disorders in pregnancy, childbirth and puerperium $(1,8 \%)$. The cesarean section was responsible for $67,7 \%$ of the births performed and $62,8 \%$ of the procedures being post-abortion curettage. It stands out theatment for complications in pregnancy $(92,8 \%)$, for complications in pregnancy $(2,4 \%)$ and for swelling, protein in urine andy hypertensive disorders in pregnancy, childbirth and puerperium (1\%). The is a feature profile of the region is not distinguished from the other regions of Brasil.

${ }^{1}$ Faculdade de Medicina de Marília (FAMEMA). Marília - SP. *E-mail: isabellatrsantos@hotmail.com 
Keywords: Pregnant women, Emergencies, Obstetrics and gynecology department, Hospital.

Resumen: El objetivo de este estúdio es identificar el perfil epidemiológico de las mujeres embarazadas atendidas em situación de urgências y emergencias en el hospital de referencia de uma instituición pública paulista. Basada em investigación epidemiológica, restropectiva, transversal de enfoque cuantitativo del tipo exploratório y explicativa. Después de análisis se verificaron variables en el perfil epidemiológico y amplios factores de riesgo de ese publico que envolvieron características socioeconômicas, morbidades preexistentes y adquiridas hasta procedimentos involucrados. Se concluye que la procedencia prevalece el municipio estudiado (72,2\%). En su mayoría (27,4\%) tenían entre 20 y 24 años. Las principales causas de atención son las complicaciones em el trabajo de parto (20\%), motivos vinculados al feto, cavidad amniótica y al parto (14\%) y edema, proteinuaria y presión arterial alta en el embarazo, el parto y el puerpério (1,8\%). La vía de parto cesárea fue responsable de $67,7 \%$ de los partos realizados y $62,8 \%$ de los procedimentos siendo el curetaje postaborto. Sobresale los tratamientos para intercorrências relacionadas al puerpério (3\%), quirúrgico de embarazo ectópico (2,4\%) y para edema, proteinuria y transtorno hipertensivos en el embarazo, parto y puerpério (1\%). Se observa um perfil característico de la región sin distinción de las demás regiones de Brasil.

Palabras clave: Embarazo, Urgencias médicas, Servicio de ginecología y obstetricia em Hospital.

\section{INTRODUÇÃO}

A mulher, no ciclo gravídico, apresenta constantes modificações morfofuncionais. Segundo Montenegro CAB e Rezende JF (2018), essas alterações fisiológicas na gestante podem ser locais ou sistêmicas incluindo os sistemas hematológico, cardiovascular, urinário, gastrointestinal e endócrino. Podem ainda, desencadear complicações obstétricas conduzindo estas mulheres aos atendimentos de urgência e emergência (MICHILIN NS, et al., 2016).

O período de gravidez na maior parte das vezes tem evolução natural, pois as diversas transformações no organismo são adaptadas ao corpo da mulher. No entanto, pode haver fatores que predispõe complicações. Esta pode ser influenciada por alguns fatores como: doenças pré-existentes ou desenvolvidas na gravidez, sócio ambientais, culturais e econômicas; que se articulam na produção de complicações a gravidez (SILVA JR, et al., 2018; BRASIL, 2012a).

Considera-se gravidez de alto risco as intercorrências maternas fetais que afetam desde a concepção, passando pelo desenvolvimento até o nascimento (MONTENEGRO CAB, REZENDE JF, 2018). Segundo a Base de Dados de Internações Hospitalares $15 \%$ das gestantes no Brasil são de alto risco, havendo, portanto, um número significativo (BRASIL, 2012b).

Os atendimentos destes casos agudos podem exigir condutas desde observação clínica até manobras de estabilização das condições vitais da mãe e do concepto. A admissão da gestante no serviço de urgência é motivo de grande expectativa nos familiares e profissionais de saúde, pois está implícito que, neste caso, o risco para à vida está associado à, no mínimo, duas pessoas (MICHILIN NS, et al., 2016).

Embora as taxas de morbi-mortalidade materna tenham reduzido no Brasil, é muito importante continuar investindo esforços, pois ainda se comportam de forma relevante. Pensar em estratégias de educação em saúde sendo possível administrar recursos como aconselhamento e prestar informações (SILVA JR, et al., 2018).

No Brasil, de acordo com dados do Ministério da Saúde, o Brasil registrou em 20161.463 casos de morte materna, das quais $92 \%$ foram consideradas evitáveis (VALADARES C, 2018). Além disso, as principais causas para este infortúnio é o não reconhecimento de sintomas graves, levando ao retardamento da procura do serviço adequado e a baixa qualidade nos atendimentos realizados (BRASIL, 2012a).

Em 2000, o Brasil foi um dos países que se comprometeu com os Objetivos de Desenvolvimento do Milênio (ODM) junto a Organização Mundial de Saúde (OMS), onde havia metas para serem compridas em até 2015. 
Uma das metas era reduzir a mortalidade materna no Brasil para 35 para cada 100 mil nascidos vivos. Em 2015, foram propostos novos objetivos para ser atingido até 2030, o chamado "Objetivo de Desenvolvimento Sustentável" (ODS), no qual, constam 18 itens. A taxa de mortalidade materna está na categoria de "Saúde e Bem Estar" e tem como finalidade reduzir para 30 mortes para cada 100 mil nascidos vivos (BRASIL, 2014).

Os profissionais da rede de atenção à saúde, compreendida da atenção básica aos serviços hospitalares de referência, devem estar aptos a identificar as vulnerabilidades, conhecer as possíveis intervenções nos casos de situações de urgência e implantar ações que proporcionam diminuição na morbimortalidade materno-fetal (SILVA JR, et al., 2018; VALADARES C, 2018; BRASIL, 2012). É indispensável aos profissionais de saúde compreender as alterações físicas, biológicas, emocionais e sociais que repercutem no período gravídico, com objetivo de proporcionar assistência qualificada de promoção de saúde e prevenção de agravo na saúde deste conjunto materno-fetal (MICHILIN NS, et al., 2016).

O contato diário no cenário de uma unidade hospitalar de uma instituição pública do interior paulista, no ano de 2018, despertou a indagação sobre o perfil das mulheres gestantes atendidas no serviço de urgência e emergência. Portanto, este estudo tem como objetivo identificar o perfil epidemiológico deste público.

\section{MÉTODOS}

Estudo epidemiológico, transversal, com abordagem quantitativa do tipo exploratória e explicativa. Tem como objetivo conhecer o perfil epidemiológico de mulheres no período de gestação e puerpério atendidas em situação de urgência e emergência no Pronto Socorro Materno Infantil de uma instituição pública do interior paulista, no período de janeiro de 2014 a abril de 2018.

Os dados coletados no Núcleo Técnico de Informação (NTI) da Instituição pública do interior paulista permitiram categorizá-las quanto a: Indicadores de ocupação do hospital, Faixa Etária das gestantes atendidas, Causas de atendimentos e Procedimentos realizados.

O local estudado constitui uma área de abrangência para 62 municípios. O hospital é de médio porte, obtendo capacidade operacional de 102 leitos nas áreas de saúde da criança e da mulher. Possui setores ambulatoriais e de internação clínico cirúrgico nas diversas especialidades, sendo uma delas a ginecologia e obstétrica.

Este estudo seguiu os preceitos das Resoluções que regulamentam a ética na pesquisa com seres humanos, tais como resolução $n^{\circ}$ 466/2012, 510/2016 e 580/2018. A realização desta pesquisa se deu após a submissão, apreciação e aprovação do projeto de pesquisa pelo Comitê de Ética em Pesquisa da Universidade Faculdade de Medicina de Marília, com emissão do parecer n 3.136.177 e Certificado de Apresentação para Apreciação Ética (CAAE) de № 03949018.4.0000.5413.

\section{RESULTADOS}

Constatou-se que a procedência das gestantes atendidas em um hospital em situações de urgência e emergência, foram provenientes de Marília, enquanto 27,8\% dos demais municípios. Ressalta-se a referência deste serviço para 62 municípios, ainda assim 72,2\% dos atendimentos realizados no período de janeiro 2014 á abril 2018.

O estudo demostrou que os indicadores de urgência e emergência obstétricas durante o período referido, há uma média de 15 mulheres atendidas na urgência e emergência obstétrica ao dia. Observa-se a capacidade planejada e operacional sendo igual e que a média de permanência do público é de três dias. Logo, esses dados podem indicar uma demanda excessiva, visto o tempo de permanência.

A faixa etária de urgência e emergência obstétricas no período do estudo aponta a média de idade das mulheres em situação de urgência e emergência atendidas foi de 20 a 24 anos (27,4\%), coincidindo com o período 
fértil (menacme). Um número significativo de adolescentes entre 15 á 19 anos (17\%) foram atendidas em situação de urgência obstétricas. Não menos preocupante, foi encontrar $1 \%$ de crianças entre 10 a 14 anos entre as mulheres atendidas em urgência.

A Tabela 1 demonstra as causas dos atendimentos de mulheres gestantes no período de janeiro 2014 a abril de 2018. Encontra-se no resultado dessa pesquisa em estudo como causa principal (22\%) de atendimento as complicações em trabalho de parto e parto, seguido de complicações que terminam em aborto com (20\%), motivos ligados ao feto, cavidade amniótica e ao parto (14\%) e edema, proteinúria e transtornos hipertensivos na gravidez, no parto e no puerpério com (1,8\%).

A Tabela 2 mostra os tratamentos realizados nos atendimentos as gestantes em situação de urgência e emergência. A principal terapêutica foi para intercorrências na gravidez $(92,8 \%)$, seguido de complicações relacionadas ao puerpério (3\%), cirúrgico de gravidez ectópica $(2,4 \%)$ e edema, proteinúria e transtornos hipertensivos na gravidez, parto e puerpério (1\%).

Em relação a procedimentos, na Tabela 3, constam 62,8\% relacionados a curetagem pós-abortamento. Quanto aos tipos de partos, na Tabela 4, mostra que o cesáreo tem maior frequência $(67,7 \%)$. O parto cesariano em gestação de alto risco prevalece em relação a parto normal para o mesmo caso, respectivamente, 53,3\% e $11,5 \%$. Ressalta-se ainda a via cesárea sendo de baixo risco corresponde a 5,6\%.

Tabela 1 - Causa dos Atendimentos relacionados à gravidez, parto e puerpério no período de janeiro 2014 a abril 2018.

\begin{tabular}{lcc}
\hline Causa dos Atendimentos relacionados à gravidez, parto e puerpério. & $\mathbf{N}$ & $\%$ \\
\hline Outros transtornos maternos relacionados predominantemente com a gravidez & 3.358 & 35 \\
\hline Complicações do trabalho de parto e do parto & 2.101 & 22 \\
\hline Complicações que termina em aborto & 1.850 & 20 \\
\hline $\begin{array}{l}\text { Assistência prestada à mãe por motivos ligados ao feto e à cavidade amniótica e por } \\
\text { possíveis problemas relatos ao parto em terceiro }\end{array}$ & 1.296 & 14 \\
\hline Edema, proteinúria e transtornos hipertensivos na gravidez, no parto e no puerpério & 753 & 0,8 \\
\hline Outras afecções obstétricas não classificadas em outra parte & 57 & 0,6 \\
\hline Complicações relacionadas predominantemente com o puerpério & 21 & 0,3 \\
\hline Feto e recém-nascido afetados por fatores maternos e por complicações da gravidez, do \\
trabalho de parto e do parto & 14 & 0,1 \\
\hline Total & 9.450 & 100 \\
\hline
\end{tabular}

Fonte: PAVELQUEIRES S, SANTOS ITRS, 2019.

Tabela 2 - Tratamentos Realizados pelas gestantes e puérperas atendidas em urgência e emergência obstétrica de janeiro 2014 a abril 2018.

\begin{tabular}{lc|c}
\hline Tratamentos Realizados & $\mathbf{N}$ & $\%$ \\
\hline Tratamentos em Intercorrências na gravidez & 1.133 & 92,8 \\
\hline Tratamento de complicações relacionadas predominantemente ao puerpério & 38 & 3,1 \\
\hline Tratamento cirúrgico de gravidez ectópica & 30 & 2,4 \\
\hline $\begin{array}{l}\text { Tratamento de edema, proteinúria e transtornos hipertensivos na gravidez, parto e } \\
\text { puerpério }\end{array}$ & 13 & 1,07 \\
\hline Tratamento de complicações de procedimentos cirúrgicos ou clínicos & 4 & 0,3 \\
\hline Tratamento com cirurgias múltiplas & 1 & 0,08 \\
\hline Tratamento clínico para contenção de comportamento desorganizado & 1 & 0,08 \\
\hline Total & 1.220 & 100 \\
\hline
\end{tabular}

Fonte: PAVELQUEIRES S, SANTOS ITRS, 2019.

REAEnf/EJNC | Vol. 4 | e4687 | DOI: https://doi.org/10.25248/REAenf.e4687.2020 
Tabela 3 - Procedimentos realizados pelas gestantes e puérperas atendidas em urgência e emergência obstétrica de janeiro 2014 á abril 2018.

\begin{tabular}{lc|l}
\hline Procedimentos Realizados & $\mathbf{N}$ & $\%$ \\
\hline Curetagem pós-abortamento/puerperal & 781 & 62,8 \\
\hline Diagnóstico e/ou atendimento de urgência em clínica médica & 364 & 29,4 \\
\hline Salpingectomia & 29 & 2,4 \\
\hline Curetagem uterina em mola hidatiforme & 23 & 1,9 \\
\hline Ressutura de parede abdominal (por deiscência total/evisceração) & 19 & 1,6 \\
\hline Cerclagem de colo do útero & 9 & 0,72 \\
\hline Curetagem semiótica c/ ou s/ dilatação do colo do útero & 9 & 0,72 \\
\hline Diagnóstico e/ou atendimento de urgência em clínica cirúrgica & 5 & 0,40 \\
\hline Laparotomia exploradora & 1 & 0,08 \\
\hline Esvaziamento de útero pós aborto por aspiração anual intrauterina & 1 & 0,08 \\
\hline Colpotomia & 1 & 0,08 \\
\hline Drenagem de abscesso de mama & 1 & 0,08 \\
\hline Total & 1.244 & 100 \\
\hline
\end{tabular}

Fonte: PAVELQUEIRES S, SANTOS ITRS, 2019.

Tabela 4 - Partos realizados em urgência e emergência obstétrica de janeiro 2014 á abril 2018.

\begin{tabular}{l|c|c}
\hline Parto Realizados & $\mathbf{N}$ & $\%$ \\
\hline Parto cesariano em gestação de alto risco & 3.341 & 53,4 \\
\hline Parto normal & 1.305 & 20,8 \\
\hline Parto normal em gestação de alto risco & 722 & 11,5 \\
\hline Parto cesariano com laqueadura tubaria & 505 & 8,7 \\
\hline Parto cesariano & 384 & 5,6 \\
\hline Total & 6.257 & 100 \\
\hline
\end{tabular}

Fonte: PAVELQUEIRES S, SANTOS ITRS, 2019.

\section{DISCUSSÃO}

O Acolhimento com Classificação de Risco (ACCR) em obstetrícia é um dispositivo que permite priorizar os atendimentos de maior risco, proporcionando melhor qualidade e resolutividade na assistência. Além de impedir a superlotação com problemas de saúde não urgentes. Visto os indicadores deste estudo, percebe-se que a capacidade planejada é igual a operacional. É necessário que haja uma articulação com as redes de atenção a saúde (BRASIL, 2014).

Em relação à faixa etária, segundo OMS (2018), a taxa da gestação na adolescência do Brasil é de $68,4 \%$ enquanto na com a América Latina que é de 65,5\%. Além disso, ainda refere que há o risco de mortalidade materna em menores de 15 anos, ainda é alto. Gestantes muito jovens apresentam um risco maior, além da imaturidade funcional de seu organismo há as repercussões psicológicas (BOUZAS IC, et al., 2014). No Brasil, a gravidez na adolescência teve uma redução significativa, comparando com ano de $2000 \mathrm{com}$ taxa de 83,6\%, 2010 com percentual de 70,9\%. Esta diminuição pode ser explicada com a divulgação de Políticas Públicas que se pautaram em educação em saúde e planejamento familiar. Percebe - se uma relevância, pois de acordo com o Inquérito Nacional sobre Parto e Nascimento feita pela Fundação Fundação Oswaldo Cruz, 66\% da gravidez em adolescentes não é planejada (VALADARES C, 2017).

Outra questão sobre a faixa etárias é que, entre 45 e 49 anos há um menor número de gestantes, equivalente a $0,3 \%$. Este fato há aspecto positivo, já que a senilidade dos ovários pode gerar gestação de risco. De acordo com ministério da saúde, gestantes com idade igual ou superior a 35 anos são consideradas parturientes tardias (BRASIL, 2012a). Porém um novo perfil de maternidade vem sendo desenvolvida, pois nota-se um crescente número de gestante na faixa de 35 a 42 anos de idade, que pode ser explicado pela maior adesão aos projetos 
de planejamento familiar e maior inserção da mulher na sociedade e mercado de trabalho, o que pode ser considerado de "maturidade materna" (ALDRIGHI JA, et al., 2016).

O estudo, observando a Tabela 1, destacam como causa de atendimento as complicações em trabalho de parto e parto (22\%). Motivos estes que encontram também no manual técnico de gestação de alto risco indicando os casos que necessitam de assistência de urgência e emergência, portanto necessários para atendimento neste serviço (BRASIL, 2012a).

$\mathrm{Na}$ Tabela 2, destacam-se os tratamentos para intercorrências na gravidez (92,8\%), seguido das complicações relacionadas ao puerpério (3\%), cirúrgico de gravidez ectópica $(2,4 \%)$ e para edema, proteinúria e transtornos hipertensivos na gravidez, parto e puerpério (1\%). Estas se relacionam com as principais causas de atendimento que são as complicações em trabalho de parto e parto (22\%), que terminam em aborto com (20\%), motivos ligados ao feto, cavidade amniótica e ao parto (14\%) e edema, proteinúria e transtornos hipertensivos na gravidez, no parto e no puerpério com $(1,8 \%)$, podendo relacionar a um prognóstico favorável da assistência de urgência e emergência obstétrica do local de estudo.

Nota-se na Tabela 1, um significativo número (20\%) de atendimento por complicação que terminaram em aborto. Esse evento corresponde à cessação antes do início do período perinatal, no qual, se caracteriza até 22 semanas completas ou se o produto da concepção pesa menos que $500 \mathrm{~g}$ ou medindo menos de $16 \mathrm{~cm}$ (BRASIL, 2011). Ocorre por algum problema no feto como em doenças genéticas ou problema no organismo materno, sejam por anomalias dos órgãos reprodutivos, infecções, doenças crônicas ou uso de substância psicoativa, como também pode ser de causa irreconhecível. Classifica-se como precoce antes de 13 semanas e tardio entre 13 e 22. Pode se classificar clinicamente como completo, inevitável/incompleto, retido, infectado, habitual e eletivo previsto em lei. É aconselhável medidas de assistência nos âmbitos biopsicossociais da mãe para melhora da assistência, mediante a situação legal (BRASIL, 2011).

Ressalta-se ainda que esse motivo de atendimento seja comum, pode ser reduzidas com ações desde educação em saúde até cuidado integral da mulher, como identificar os fatores biopsicossociais, de forma minuciosa e inserir a rede social dessa mulher para obter uma assistência holística (CARVALHO SM, PAES GO, 2014).

Outra questão sobre a causa de atendimento é que $14 \%$ dos casos foram são ligados a feto e a cavidade amniótica. O líquido amniótico (LA) possibilita segurança, evitando traumas e permitindo um desenvolvimento adequado para o feto. É um problema quando o valor dele está abaixo ou acima de seu volume adequado, podendo chamar respectivamente oligoidrâmnio ou polidrâmnio (MONTENEGRO CAB, REZENDE JF, 2018).

A redução causa anomalias fetais e retardo do crescimento intrauterino, compressão do cordão umbilical e consequentemente sofrimento fetal. No entanto, segundo o Manual de Gestação de Alto Risco a maior causa de diminuição é a rotura prematura de membrana, representando cerca de um quarto dos casos de redução e consequência deste o trabalho de parto prematuro (BRASIL, 2012a). O aumento excessivo de líquido é menos comum, porém, está relacionado á malformações fetais, alterações placentárias podendo levar a mortalidade perinatal.

Uma das causas de atendimento se relaciona com edema, proteinúria e síndromes hipertensivas, e corresponde $0,8 \%$. Atualmente a principal causa de morte materna no Brasil e no mundo são as síndromes hipertensivas da gravidez e são considerados evitáveis (VALADARES C, 2018). Caracterizada pelo nível de pressão arterial maior ou igual a 140/90 mmHg (MONTENEGRO CAB, REZENDE JF, 2018).

Podendo ser classificadas em hipertensão arterial crônica (HAS) quando é diagnosticado antes da vigésima semanas de gestação e após dozes semanas pós-parto; a hipertensão gestacional após 20 semanas. Como complicações desta última pode ser acompanhada de proteinúria. Quando isto acontece denomina-se de PréEclampsia. Ainda há a Pré-Eclampsia superposta a HAS crônica, onde além dos fatores da Pré-Eclampsia há 
plaquetopenia ou anormalidades da função hepática, em gestantes portadoras de HAS crônica. Quando associado a este fator, tem-se a DHEG agravada e, quando associada à crise convulsiva denomina-se Eclâmpsia. Um estágio que compromete a vida da gestante e a instalação da Síndrome de Hellp que representa a associação de hemólise, plaquetopenia e elevação de enzimas hepática. No local estudado, cerca de $2 \%$ dos tratamentos do local estudado, são para terapêutica de edema, proteinúria e transtornos hipertensivos na gravidez, parto e puerpério (MONTENEGRO CAB, REZENDE JF, 2018).

Neste estudo, segundo a Tabela 1, as complicações relacionadas ao puerpério são $0,3 \%$ das causas de atendimento. Não estão entre as maiores taxas, porém sabe-se que dentre as taxas de morbimortalidade materna no Brasil essas intercorrências são relativamente altas (BRASIL, 2012a; FERNANDES BB, et al., 2015).

Cerca de $92 \%$ das mortes maternas evitáveis e dentre elas está a hemorragias e infecção puerperal. (VALADARES C, 2018; BRASIL, 2011). Nessa fase, a mulher se encontra no pós-parto que pode ser divida em: puerpério imediato que é desde o nascimento até primeiras 24 horas, precoce até sete dias e tardio até seis semanas (MONTENEGRO CAB, REZENDE JF, 2018).

Quanto aos tipos de partos, na Tabela 4, mostra que o cesáreo tem maior frequência $(67,7 \%)$ evidenciando uma discrepância em relação à recomendação. Observa-se o parto cesariano em gestação de alto risco prevalece em relação a parto normal para o mesmo caso, respectivamente, $53,3 \%$ e $11,5 \%$. Ressalta-se ainda a via cesárea de baixo risco corresponde a 5,6\%, demonstrando uma taxa inapropriada. Segundo as Diretrizes de atenção a Gestante, cerca de $55,6 \%$ dos partos são cesáreos (BRASIL, 2015).

Essa taxa no serviço público é relativamente menor quando comparado ao privado, sendo respectivamente $40 \%$ e $84 \%$. Segundo a OMS (2018) o Brasil é o segundo país com mais índice de parto cesáreo, nos quais, estão em destaque às regiões brasileiras sul, sudeste e centro-oeste, segundo os dados do DATASUS de 2017 (SOUZA C, ZANLORENSSI G, 2019).

A taxa de cesárea indicada pela OMS (2015) que seria considerado adequado e justificável apenas de 10 a $15 \%$ dos partos. A condição de risco da gestante e sua opção de escolha influencia o tipo de parto. É necessário que a gestante tenha conhecimento, ainda no pré-natal sobre benefícios e riscos de tais vias, promovendo sua autonomia na escolha do método para nascimento de seu filho. As "Diretrizes de atenção a gestante" é um recurso disponível para orientação (BRASIL, 2015).

Nota-se um significativo número, na Tabela 3, cerca de $10 \%$ de procedimento de curetagem pósabortamento/puerperal podendo se relacionar com a Tabela 2, cujo $22 \%$ causas de atendimentos são complicações que termina em aborto e complicações relacionadas com o puerpério. A Curetagem é uma raspagem intraútero, realizada via vaginal com um instrumental chamado cureta. É indicado nos casos de abortos retidos ou incompletos, ou investigação diagnóstica e tratamentos (BRASIL, 2012a).

Ainda na Tabela 3, nota-se a salpingectomia, com cerca de $0,1 \%$, procedimento com finalidade de retirada das trompas uterina, podendo ser unilateral ou bilateral. Segundo FEBRASGO (2017) é indicada em casos de paciente com gravidez ectópica, ectópica rota, lesão tubária extensa e quando há prole constituída, uma vez este procedimento pode deixar a mulher infértil. Essa técnica cirúrgica esta associada com a prevenção de câncer de ovário. Pode-se relacionar essa terapêutica, a cirurgia de gravidez ectópica na Tabela 2, que corresponde a 3\% sendo a terceira maior taxa de tratamentos realizados.

Portanto, o atendimento deste hospital constata maior procedência o local de estudo, apesar da referência para 62 municípios. Apresenta um perfil característico e não encontra uma contradição das outras regiões do Brasil. Sendo em sua maioria gestantes jovens, indicando a fase propícia para o período reprodutivo.

As principais causas de atendimento são as complicações em trabalho de parto e parto, seguido de complicações que terminam em aborto, motivos ligados ao feto, cavidade amniótica e ao parto e edema, proteinúria e transtornos hipertensivos na gravidez, no parto e no puerpério. Em relação os tratamentos, a maior 
incidência é para intercorrências na gravidez, seguido complicações relacionadas ao puerpério, cirúrgico de gravidez ectópica e terapêutica para edema, proteinúria e transtornos hipertensivos na gravidez, parto e puerpério. O procedimento em destaque foi à curetagem pós-abortamento. Assim, nota-se uma resolutividade efetiva visto a causa de atendimentos, tratamentos e procedimentos de cada um referido. Vale ressaltar que as causas citadas são de relevância para a morbimortalidade materna.

A via de parto cesárea foi responsável por mais da metade dos partos realizados durante o período do estudo, ultrapassando a taxa desta no Brasil e além de estar em desconformidade com as recomendações do Ministério da Saúde e da Organização Mundial de Saúde.

\section{CONCLUSÃO}

O estudo possibilitou reconhecer e caracterizar o perfil epidemiológico de gestantes em situação de urgência e emergência. Compreenderam-se os antecedentes obstétricos e a conjuntura de condições sociodemográficas e econômicas. Sugere-se um investimento na promoção e prevenção do planejamento familiar, pré-natal, parto e puerpério. Sendo fundamental reconhecer os indicadores, estabelecer metas e traçar o perfil para o planejamento. Propõe-se a articulação das redes de atenção á saúde, visando a integralidade e uma qualificação profissional para identificar e solucionar precocemente riscos ou alterações neste período. A gestação de alto risco é um significativo problema de saúde pública, sendo necessário o uso de estratégias para melhorar a qualidade dos serviços e a clínica ampliada para uma assistência holística e longitudinal, a fim da redução da morbimortalidade materna.

\section{REFERÊNCIAS}

1. ALDRIGHI JA, et al. Vivência de mulheres na gestação em idade tardia. Revista Gaúcha de Enfermagem, Porto Alegre, 2017;39(1):1-9.

2. BOUZAS IC, et al. Gravidez na adolescência: uma revisão sistemática do impacto da idade materna nas complicações clínicas, obstétricas e neonatais na primeira fase da adolescência. Adolescência \& Saúde, Rio de Janeiro, 2014;11(3): 721.

3. BRASIL. Ministério da Saúde. Secretaria de Atenção à Saúde. Departamento de Ações Programáticas Estratégicas. Manual de acolhimento e classificação de risco em obstetrícia. Estratégicas. Brasília: Ministério da Saúde, 2014.

4. BRASIL. Ministério da Saúde. Secretaria de Atenção à Saúde. Departamento de Ações Programáticas Estratégicas. Gestação de alto risco: manual técnico. Brasília: Ministério da Saúde, 2012a.

5. BRASIL. Secretaria Executiva. Departamento de Informática do SUS. Coordenação Geral de Informática de Informações de Saúde. Sistema de Informações Hospitalares do SUS - SIH/SUS. Gestação de Alto Risco, 2012b.

6. BRASIL. Secretaria de Ciência, Tecnologia e Insumos Estratégicos. Departamento de Gestão e Incorporação de Tecnologias em Saúde. Diretrizes de Atenção à Gestante: a operação cesariana. Ministério da Saúde. Brasília, 2015.

7. BRASIL. Secretaria de Políticos de Saúde. Área Técnica de Saúde da Mulher. Parto, aborto e puerpério: assistência humanizada à mulher. Brasília: Ministério da Saúde, 2011.

8. CARVALHO SM, PAES GO. Integralidade do cuidado em enfermagem para a mulher que vivenciou 0 aborto inseguro. Escola Anna Nery Revista de Enfermagem, Rio de Janeiro, 2014; 18(1):130-135.

9. FEDERAÇÃO BRASILEIRA DAS ASSOCIAÇÕES DE GINECOLOGIA E OBSTETRÍCIA. Mola hidatiforme é câncer? São Paulo: FEBRASGO, 2017.

10. FERNANDES BB, et al. Pesquisa epidemiológica dos óbitos maternos e o cumprimento do quinto objetivo de desenvolvimento do milênio. Revista Gaúcha de Enfermagem, Ribeirão Preto, 2015;36(no.spe): 192-199,

11. MICHILIN NS, et al. Análise dos atendimentos obstétricos realizados pelo Serviço de Atendimento Móvel de Urgência. Revista Brasileira de Enfermagem, Botucatu, 2016; 69(4): 669-675.

12. MONTENEGRO CAB; REZENDE JF. Obstetrícia. 14르 ed. Rio de Janeiro: Guanabara Koogan, 2018.

13. OBJETIVOS DE DESENVOLVIMENTO SUSTENTÁVEL. Sistema de Monitoramento de Indicadores. Relatórios Dinâmicos. Mortalidade materna cresce no Brasil. Curitiba: SESI PARANÁ, 2018. 
14. ORGANIZAÇÃO PAN-AMERICANA DA SAÚDE/ORGANIZAÇÃO MUNDIAL DA SAÚDE. Taxa de gravidez adolescente no Brasil está acima da média latino-americana e caribenha Brasília: OPAS/OMS, 2018.

15. ORGANIZAÇÃO PAN-AMERICANA DA SAÚDE; ORGANIZAÇÃO MUNDIAL DA SAÚDE. Folha informativa: Mortalidade materna. Brasília: OPAS/OMS, 2018.

16. SILVA JR, et al. Indicadores da Qualidade da Assistência Pré Natal de Alto Risco em uma Maternidade Pública. Revista Brasileira de Ciências da Saúde, Maranhão, 2018. 22(2):109-116.

17. SOUZA C, ZANLORENSSI G. Os tipos de parto no Brasil e os locais de sua ocorrência. Nexo Jornal LTDA, São Paulo, 2019.

18. VALADARES C. Ministério da Saúde investe na redução da mortalidade materna. Agência Saúde. Brasília, 2018.

19. VALADARES C. Gravidez na adolescência tem queda de 17\% no Brasil. Agência Saúde, Brasília, 2017.

20. ORGANIZAÇÃO PAN-AMERICANA DA SAÚDE; ORGANIZAÇÃO MUNDIAL DA SAÚDE. Declaração da OMS sobre Taxas de Cesáreas. Brasília: OPAS/OMS, 2015. 